\title{
Rock Music in Contemporary China: An Ideological Arena*
}

\author{
ZHOU Xiao-yan \\ Shanghai Jiao Tong University, Shanghai, China
}

\begin{abstract}
The rock music in contemporary China is a filed for the folk, official, elite and other multi-element ideology competition. Wang Feng is a winner walking on the ideological balance beam. After deconstructing Cui Jian's grand narrative mode and strong critical feature, his works have been endowed with heavy critical color and reflection value by a grassroots band named "Xuriyanggang”. Besides, Wang Feng's works have eliminated the distinction between the official and folk feature, elegance and worldly feature, as well as elite and mass. To a large extent, they have defined the rock music in contemporary China, and pushed the Chinese rock to the mainstream market. Consequently, the Chinese rock has been gradually developed into multiple and compound culture modes.

Keywords: Chinese rock, ideology, arena
\end{abstract}

\section{Introduction}

As a music style originating from Europe and America, rock music gives expression to the theme about freedom and criticizes the reality, which is the main existence value for the rock music, and also the main difference between the rock music and the pop music (substantive characteristic: commodity). Rock music was not brought into China until 1980s. It reached the climax at the beginning of 1990s. After 1994, it almost got collapsed but fortunately did not withered away. Cui Jian, honored as "the Father of Chinese Rock", is a representative for the early rock \& roll singers in China. Around 1994, he pushed the Chinese rock music to the zenith together with other rock singers and bands. Most rock music lyrics composed by Cui Jian present the theme about freedom, liberation and rebellion, which shows obvious western rock feature. However, the early Chinese rock represented by Cui Jian tends to have big difference from the western rock on the manifestation form. For the former one, the yell, roar and keyed feature are staggered to happen. It does not have as strong and exaggerated metal temperament and strange colors as that of the western rock. As a result, it is greatly different from the western rock. If it was said that, the rock music entered into the mainstream sequence (non-dominant) of Chinese Mainland momentarily at the beginning of 1990s due to Cui Jian's yell, it also can be said that Chinese rock entered into the "mainstream market" and "mainstream ideology" camps for the second time due to Wang Feng after 2010.

\footnotetext{
* Acknowledgements: This paper is supported by: (1) Jiangsu Social Science Funding Project "Research on Chinese Pop Music" (13ZWD019); (2) China National Find of Social Sciences "the Research of Fundamental Problems of the Contemporary Aesthetic and Criticism Forms" (15ZDB023).

ZHOU Xiao-yan, Ph.D. School of Humanities, Shanghai Jiao Tong University. Her research field covers: Theory of Literature and Art, Critical Theory, Marxism and aesthetics.
} 


\section{Cui Jian: Symbolic Figure of Chinese Rock Music in 1980s}

In 1980s, shortly after the ice of political ideology in Chinese Mainland was defrosted, Cui Jian’s song "I Have Nothing” stood out unexpectedly in 1986, which awoke the youth in that generation. It symbolizes the birth of the Chinese rock music. In this song, there are 23 letters of "I", which is undoubtedly regarded as the rebellious behavior in the era of "Collectivism Supreme". Cui Jian has possessed the first fan group in China by virtue of this song-Backup Group organized by Peking University. His fans are regarded as the most senior fans that stand up and listen to the songs in China. Cui Jian expresses the thought and anger through the songs, which is the symbol of the rock music in an era. He is not only honored as "the Father of Chinese Rock Music", but also regarded as a tutor for the people in that generation. With regard to the anti-tradition, anti-dominance, and anticonsumerism, his songs have certain enlightenment significance among the public. Therefore, he has been written into the literature history of contemporary China as a "troubadour".

After "I Have Nothing”, Cui Jian’s "Fake Monk”, “Girl in the Flower Room”, and “A Piece of Red Cloth” have aroused great influence. Wang Shuo, a famous writer, once said, "My tears nearly dropped after I listened to 'A Piece of Red Cloth' at the first time. Its lyrics were really so close to our life. At that time, I really felt what were written under our pens with thousands of words was not as good as her simple words.” Since 1986, although Cui Jian's works have popped into people’s mind from time to time, Cui Jian has not disappear, and his works "Rock 'n' Roll on the New Long March”, “Girl in the Flower Room”, “Fake Monk” and others have highlighted the image of "walking”, i.e. walking out, which shows the psychology of escaping. After about ten years of accumulation, after his work "Balls under the Red Flag” came into being in 1994, Cui Jian became more rebellious.

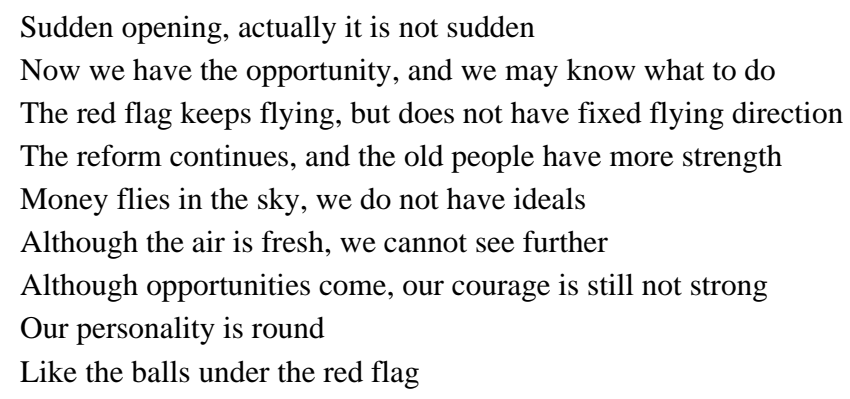

(“Balls under the Red Flag”, written and composed by Cui Jian)

In the song "Balls under the Red Flag”, Cui Jian continues to show the firm and liberal personality. However, with the prosperity of the culture and art market, his works were quickly submerged by the tide of the commodity, as people who were busy in earning money did not have enough time to show their anger and rebellion. Over ten years later, Cui Jian realized he did not have the inspiration for interacting with the era, and he also believed it might be the main cause for his unwilling to complete the works. Up to 2012, Cui Jian had not released albums for seven years in succession. He even had not held large-scale concerts for 22 years. After 2012, his tours and new albums did not evoke great repercussions.

Compared with his rock singer identity, Cui Jian is more like a noble medium. In addition, previous Cui Jian and his previous works show the antagonism feature of the folk ideology and official ideology. However, the 
current Cui Jian and his film art show the difference on the aesthetic standards between the elites and the mass, the elegant culture and secular culture. Cui Jian is expected to realize his commitment of rock music soon. The object criticized is strong, and it is not feasible to use big stick to beat the mosquito. Certainly, such criticism is established based on the competition of the elites, officials, folks, recruitment, commerce, and dominant ideology.

\section{Wang Feng: A Rock Singer Walking on the Ideological Balance Beam}

Since Cui Jian started the Chinese rock march in 1986, it has already 20 years, during which, there are many ups and downs. The road for the Chinese rock music is not so easy to step on. Usually, the rock singers sigh with emotion and feel puzzled in the commercial storm. Different from the theme of the western rock music, the antagonism of the Chinese rock music is almost presented through its dispute with the commercial ideology, while the western rock music confronts the politics, system and society, which is the presentation for the collective doubt brought by the old belief, tradition and consciousness as it cannot completely govern the new life. Such difficulty must be encountered by Chinese rock during its development, and its occurrence is also inevitable at the crash and blending phase of the traditional, modern, western and oriental culture in the pluralistic times of the value.

Similar to the initial stage of the Chinese rock, after 2000, the audiences in Chinese Mainland still could not accept the "knocking of the heavy metal" with the theme about publicizing the sex, death, etc. However, except caring what a rock singer sings, the public gradually care how he sings and whether it can be accepted. Therefore, Wang Feng, who is the pioneer in the rock music, and shows public, dominant and leading role in this circle, has become a winner walking on the ideological balance beam in this era. He has pushed the Chinese rock to the mainstream market. In August of 2012, Wang Feng accepted the interview from Yang Lan in the program "Her Village”. What Yang Lan said is regarded as detailed and awkward-sounding footnote for "balance of Wang Feng's style": no pursuit for the airy thinking is not equal to giving up expressing the anger; expressing the rebellion and liberty theme by including them into the encouragement theme does not mean it is not sharp; that the feature is not expressed obviously does not mean the demands for exploiting the social truth is not strong; actively entering into the mainstream media and stage to give expression does not mean losing the essence of being a rock singer. Obviously, such assessment is only a kind of play on words or can be regarded as saying kind words from the viewpoint of the Chinese tradition. Therefore, it cannot conceal the commercial feature of Wang Feng's style for rock music.

From “Good Night, Beijing”, "Little Bird”, “Fly Higher”, "Made In China Remix” to "Life Asks for Nothing”, Wang Feng's style is the same as Cui Jian in recording the transition of the era and expressing the life (pleasure, anger, sorrow, joy) of ordinary people. In their own era, they have the targeted strength. In fact, to a great extent, Wang Feng's "mainstream rock” routine is formed when he kept up with Cui Jian. During this period, he admired and imitated Cui Jian, as well as his overstep on the commerce and recreation. However, as a whole, Wang Feng's rock theme is not as brilliant as Cui Jian's. In the interviewing with Yang Lan in "Her Village”, Wang Feng once said that, “A rock singer and a singer-composer firstly hopes to arouse the public's resonance. But, such resonance is not metaphysical or grand idea. The singer is only a lead, gathering all people together. In his concert, he expects that, in the three hours, the listeners can feel they are not alienated by the 
society and the crowd, not doubted by others, and then truly restore own identity."

Regarding "Fly Higher”, perhaps Wang Feng praised himself as a little bird, and started to express himself based on the theme about ordinary and encouragement. There is some metaphorical meaning when he sought for public acknowledgement and resonance. Therefore, compared with Cui Jian, it is more suitable to regard Wang Feng's rock ideal as the ideology and commercial strategy. Thus, what makes Wang Feng select such method for “rock”? With regard to this question, Wang Feng once said, "I released two albums at the end of 1997 and 1998. 'Good Night, Beijing' became popular but I still could not afford the house rent. But, for me, the most terrible thing is not out of pocket; instead, when you do not have money, you are so popular with many people. However, how an artist who cannot guarantee a basic life continues his creation? Besides, the most awful thing is that, when you are poor and sensitive, such sensitive thought resulting from the material exhaustion enables the artists to achieve more creation inspiration, so that their works must be better.” But anyway, Wang Feng has become more popular since "Fly Higher" came into being in 2004. In 2011, his song "In Spring” was well-known in China. Billions of migrant workers realized the life status the same as theirs from the song, and suffered the pain with sympathetic visage.

Through holding many concerts, Wang Feng was gradually accepted by the public, and rock music also started to be accepted. To a great extent, Wang Feng defines the rock music of the contemporary China. The public in Chinese Mainland has gradually achieved consensus towards the Chinese rock: singing the rock music is not noisy and dispirited all the time, and it can relieve the emotion and encourage people; not all rock music are filled with death odor, and it can be inspirational and positive. Obviously, it is not the rock related to the origin of the European and American rock; instead, it is rock of Contemporary China.

Wang Feng has brought hope to many Chinese rock singers and creators, which likes Cui Jian rendered hope to Wang Feng previously. At present, it seems that Wang Feng has already realized the "mainstream" desire he insisted on when he was young. Simply speaking, the "mainstream" of both does not have completely same cultural significance.

\section{“Xuriyanggang” Band: Interaction Between Chinese Rock and Society}

Wang Xu and Liu Gang are migrant workers. They sang “In Spring” loudly in the rough rental house. In the video, both of them sang with their shirts off and smoked with sweat streaming down their backs. When it came to the climax of the song, Wang Xu closed his eyes, raised his head and sang loudly. Besides, the blue veins on his neck were visible. Many empty beer bottles were disorderly scattered on the desk, which seems to indicate they led a poor life. Such scene was shot by their friends through a mobile phone, and uploaded to the internet without any processing. Gradually, it got high click rate and repost rate. Their unsophisticated songs moved many migrant workers. Most workers felt comfortable after hearing their unsophisticated songs that were out of tune. Meanwhile, such rough video changed Wang Xu and Liu Gang's destiny, and brought them into a new spring. The net friends rendered them a funny name "Xuriyanggang", and voted for them, so as to ensure their dreams would come true. Fortunately, they sang on the stage of Spring Festival gala evening held by China Central Television, and became a popular grassroots band over the country. At that time, "Xuriyanggang” became a spokesperson for the migrant workers who account for the largest population. 
At that time, a great majority of people held that, Wang Feng's "In Spring” was already so excellent, but the unusual cover version created by the grassroots band "Xuriyanggang” moved more people than Wang Feng's. From the viewpoint of the social ideology, perhaps it can be regarded as a blowout of popular will, as the disparity between the rich and the poor was so serious, and the material and spirit shortage and anger, sense of lose, and anguish resulted in great mental stress for the unprivileged classes. People longed for some channels to release such emotion, while "Xuriyanggang” appeared at the right moment. Certainly, it also indicates that the rock performed by the wooden guitar with rebellion and critical spirit has not gone way in Contemporary China. However, it still has wide mass basis, which explains the main cause for the following status: why people knew "Xuriyangguang” sang out of tune, but it still aroused resonance among the public.

The history is always surprisingly similar. The story in "In Spring" in 2011 is quite similar to "I Have Nothing” in 1986. Besides, their lyrics include the meaning of "I Have Nothing”. In 1998, Cui Jian accepted an interviewing and analyzed why "I Have Nothing" could achieve success. He said, "I believe the content and pattern of the music should be uniform, which presents the social problems. If this song is released at present, I think no one will pay attention to it. But, fortunately, that era was kept up with just in time." ${ }^{1}$ At that time, if "I Have Nothing” was not sung by Cui Jian who was little known at that time, but it was sung by a famous singer, what about the consequence? Did this song still arouse such great response? Perhaps Cui Jian was not able to become the first rock singer. Moreover, "I Have Nothing” may not be regarded as the first Chinese rock music. It even may be regarded as a common love song, and forgotten by people in short term.

It is interesting that "Xuriyanggang" cannot be compared with Cui Jian and Wang Feng who have accepted the regular music education since they were little children. But anyway, the rock for emotional disclosure was paid great attention to and sung by so many people for the first time due to "Xuriyanggang", which is an indisputable fact. In fact, it is because of "Xuriyanggang” that Wang Feng's old work "In Spring” became well-known overnight. It became influential yell from the underclass of the society, and it was endowed with relatively strong political significance. However, it is what Cui Jian has pursued all along — make Rock become a cultural force, and achieve sufficient capability to get involved in the politics and reflect the social problems. In the song "In Spring”, the modernistic critique presents the critique towards the urbanization life. It also shows that the migrant workers long for the earthy ideals, which likes the person described in "In Spring” performed by "Xuriyanggang”. He did not demand for others' understanding and sympathy, as well as the urban containment. Instead, he firmly stepped forward, and conquered the city with his firm gesture, which presents strong social critical consciousness. It seems to inform people in a loud voice that, the ideal is not the patent of the city people, and even the underprivileged people have their own ideals. Even though they lack wealth, knowledge and resource, it still cannot restrict their grand ideal and spirit. Briefly, the success of "Xuriyanggang" has strong people-oriented consciousness, and a success for the expression of public opinion. It fully reflects the pop music including Wang Feng's rock style. What's more, it is not only an important artistic pattern for entering into the heart of the public, but also an important way of getting involved in the politics and culture, and further illustrates that Chinese rock is an ideological arena with multiple and compound cultural attributes.

\footnotetext{
${ }^{1}$ Research on Literature and Art Theory: Cui Jian, Mao Danqing. Fly Over “Island” of Rock, 1998. No.1: Page 40.
} 


\section{Conclusion}

According to Marx's theory-material production restricts spiritual production, any artistic patterns or artistic production theories are always subject to and adapt to the specific production modes. Therefore, the Chinese rock is the product from the crashing of the western and Chinese art. It is impossible to possess all features of the western rock. From the viewpoint of the time, Wang Feng is the representative figure of the third-generation rock singers after Cui Jian and Zhang Chu. Growing up in the strong ideological atmosphere-market economy era and "rise of great powers", Wang Feng has different rock ideals from the previous two generations. His "mainstream rock” practice deliberately escapes from the heavy social criticism theme, and almost does not present the social structural contradictions and system oppression. Besides, it lays particular stress on expressing encouragement, adamancy, and other individual emotion. However, on one hand, Wang Feng's works deconstruct Cui Jian's grand narrative mode and strong critical characteristics. On the other hand, with the emergence of "Xuriyanggang” and under the specific era and social background, Wang Feng's works are re-endowed with heavy critical color and reflection value by virtue of the power of the netizens. It indicates that Chinese rock inevitably becomes an ideological arena as it is included in the musical manifestation pattern, non-mainstream and critical factors of the theme and performance styles. However, Wang Feng is a typical winner walking on the ideological balance beam. His works eliminates the distinction between the official and folk feature, elegance and worldly feature, as well as elite and mass. To a certain extent, they have defined the artistic characteristics of the rock music of contemporary China in the mind of the public, and pushed the Chinese rock to the mainstream market. The rock has already been developed into multiple and compound artistic pattern.

\section{References}

Angela McRobbie. (2007). The Uses of Cultural Studies. (Li Qingben, Trans.). Beijing: Peking University Press. John Storey. (2007). Storey: Coupling of Memory and Desire-Change and Power in British Culture studies. (Xu Delin, Trans.). Guilin: Guangxi Normal University Press.

Gustave Le Bon. (2007). A Study of the Popular Mind. (Feng Keli, Trans.). Guilin: Guangxi Normal University Press. Morris Dickstein. (2007). Gates of Eden: American Culture in 1960s. (Fang Xiaoguang, Trans.). Nanjing: Yilin Press. Matthew Arnold. (2008). Culture and Anarchy. (Han Minzhong, Trans.). Beijing: Sanlian Bookstore. 